\title{
Depression and Health-Related Quality of Life in Chronic Obstructive Pulmonary Disease
}

\author{
Theodore A. Omachi, MD, MBA ${ }^{1}$, Patricia P. Katz, $\mathrm{PhD}^{2}$, Edward H. Yelin, $\mathrm{PhD}^{2,3}$, Steven E. \\ Gregorich, $\mathrm{PhD}^{4}$, Carlos Iribarren, MD, MPH, $\mathrm{PhD}^{5}$, Paul D. Blanc, MD, MSPH ${ }^{1,6}$, and Mark \\ D. Eisner, MD, MPH ${ }^{1,6}$ \\ Theodore A. Omachi: omachi@ucsf.edu; Patricia P. Katz: patti.katz@ucsf.edu; Edward H. Yelin: ed.yelin@ucsf.edu; Steven \\ E. Gregorich: gregorich@medicine.ucsf.edu; Carlos Iribarren: carlos.iribarren@kp.org; Paul D. Blanc: paul.blanc@ucsf.edu; \\ Mark D. Eisner: mark.eisner@ucsf.edu \\ ${ }^{1}$ Division of Pulmonary \& Critical Care Medicine, Department of Medicine, University of California, \\ San Francisco \\ 2 Institute for Health Policy Studies, University of California, San Francisco \\ ${ }^{3}$ Division of Rheumatology, Department of Medicine, University of California, San Francisco \\ 4 Division of General Internal Medicine, Department of Medicine, University of California, San \\ Francisco \\ ${ }^{5}$ Division of Research, Kaiser Permanente, Oakland, CA \\ ${ }^{6}$ Division of Occupational and Environmental Medicine, Department of Medicine, University of \\ California, San Francisco
}

\section{Abstract}

Background-Prior research on the risk of depression in COPD has yielded conflicting results. Furthermore, we have an incomplete understanding of how much depression versus respiratory factors contribute to poor health-related quality of life.

Methods-Among 1202 adults with COPD and 302 demographically-matched referents without COPD, depressive symptoms were assessed using the 15-item Geriatric Depression Score (GDS). We measured COPD severity using a multifaceted approach, including spirometry, dyspnea, and exercise capacity. We used the Airway Questionnaire 20 and the Physical Component Summary Score to assess respiratory-specific and overall physical quality of life, respectively.

Results-In multivariate analysis adjusting for potential confounders including sociodemographics and all examined comorbidities, COPD subjects were at higher risk for depressive symptoms (GDS $\geq 6$ ) than referents (odds ratio [OR], 3.6; 95\% confidence interval [CI], $2.1-6.1 ; \mathrm{p}<.001$ ). Stratifying COPD subjects by degree of obstruction on spirometry, all subgroups were at increased risk of depressive symptoms relative to referents ( $\mathrm{p}<.001$ for all). In multivariate analysis controlling for COPD severity as well as sociodemographics and comorbidities, depressive symptoms were strongly associated with worse respiratory-specific quality of life (OR, 3.6; 95\% CI $2.7-4.8 ; \mathrm{p}<$. $001)$ and worse overall physical quality of life (OR, 2.4; 95\% CI, $1.8-3.2 ; \mathrm{p}<.001)$.

Corresponding Author: Theodore A. Omachi, M.D., M.B.A., University of California, San Francisco, Box 0111, 505 Parnassus Ave, San Francisco, CA 94143-0111, Telephone (415) 476-7351, Fax (415) 814-5770, e-mail: omachi@ucsf.edu.

Publisher's Disclaimer: This is a PDF file of an unedited manuscript that has been accepted for publication. As a service to our customers we are providing this early version of the manuscript. The manuscript will undergo copyediting, typesetting, and review of the resulting proof before it is published in its final citable form. Please note that during the production process errors may be discovered which could affect the content, and all legal disclaimers that apply to the journal pertain. 
Conclusions-Patients with COPD are at significantly higher risk of having depressive symptoms than referents. Such symptoms are strongly associated with worse respiratory-specific and overall physical health-related quality of life, even after taking COPD severity into account.

\section{Keywords}

Depression; Health Status; Pulmonary Disease; Chronic Obstructive; Quality of Life

\section{INTRODUCTION}

A primary objective of treatment for patients with chronic disease is to improve health-related quality of life. ${ }^{1}$ For patients with chronic obstructive pulmonary disease (COPD), pulmonary rehabilitation is known to improve health-related quality of life, but this benefit is not fully explained by improvement in cardio-respiratory function. ${ }^{2-4}$ For example, a recent Cochrane meta-analysis concluded that pulmonary rehabilitation programs significantly improved health-related quality of life, even though the improvement in exercise capacity was below the threshold of clinical significance. ${ }^{4}$ This finding raises the intriguing possibility that psychosocial factors, such as depression, are critical determinants of health status in COPD.

Depression is thought to be associated with worse health status in patients with COPD, but studies on this subject have generally been hampered by either small sample sizes or incomplete information to adjust for COPD severity.${ }^{5-7}$ Moreover, while depression appears to be more common in COPD patients than in the general population, there have been few studies addressing this question. ${ }^{5,8}$ One systemic review concluded that the evidence for a significant risk of depression in COPD patients remained inconclusive. ${ }^{9}$ Indeed, some studies have found an increased level of depression in patients with COPD, ${ }^{10,11}$ while others have not. ${ }^{12,} 13$

Our study uses a large observational cohort to study depressive symptoms in COPD. We hypothesized that individuals with COPD would be more likely to have depressive symptoms than demographically matched referent subjects without COPD, that more severe COPD would be associated with a higher likelihood of having depressive symptoms, and that depressive symptoms would be strongly associated with health-related quality of life even after controlling for COPD severity.

\section{METHODS}

\section{Participants}

The Function, Living, Outcomes, and Work (FLOW) study is an ongoing cohort study of patients with COPD and matched referents without COPD. ${ }^{14}$ The cohort was derived from members of Kaiser Permanente (KP),. Patient recruitment has previously been described in detail. ${ }^{14}$ Briefly, we identified all adult KP members, living within a 30-mile radius of our research clinic, who were recently treated for COPD. ${ }^{14}$ The age range was restricted to 40-65 years because an important focus of the FLOW study is examining the long-term prevention of COPD-associated morbidities. Using KP databases, we identified all patients who met each of two criteria: one based on health-care utilization and the second based on medication prescription. The health-care utilization criterion was $\geq 1$ outpatient visits or hospitalizations for COPD over the prior 12 months. The medication criterion was $\geq 2$ prescriptions for a COPDrelated medication during a 12-month window surrounding the COPD utilization date. We previously compared this algorithm to medical record review and demonstrated that it accurately identifies adults with COPD. ${ }^{15}$

We recruited 1,212 COPD patients who completed both structured telephone interviews and research clinic visits. Ten subjects were excluded because they did not meet the Global 
Initiative for Chronic Obstructive Lung Disease (GOLD) criteria for COPD based on interviews and spirometry, ${ }^{16}$ yielding a COPD cohort of 1202 subjects.

We aimed to recruit 300 control subjects without COPD. We initially identified 373 referent subjects, without historical utilization for COPD, who were matched to COPD subjects by age, gender, and race. By design, we excluded 71 subjects who had spirometric evidence of airway obstruction at the time of research clinic evaluation, leaving 302 referent subjects.

The study was approved both by the University of California, San Francisco Committee on Human Research and the Kaiser Foundation Research Institute's institutional review board and all participants provided written informed consent.

\section{Measurements}

As previously described, subjects underwent structured telephone interviews followed by a research clinic visit. ${ }^{14}$ Interviews obtained medical comorbidities, tobacco history, sociodemographic characteristics, and the 15-item short-form Geriatric Depression Scale (GDS). We chose the GDS because it was developed to counter the problem of overlap between symptoms of a physical illness, such as COPD, and the somatic symptoms considered indicative of depression. ${ }^{9}$ The GDS has been validated both in non-geriatric populations generally as well as specifically in younger adults with obstructive lung disease. ${ }^{17-19}$ Using a cut-point of 6 or more symptoms, the GDS has a sensitivity of $88 \%$ and a specificity of $62 \%$ compared with structured clinical interview for diagnosing major depression. ${ }^{20}$ Following precedent, we therefore defined depressive symptoms as present if subjects reported $\geq 6$ out of 15 possible symptoms on the GDS. ${ }^{21}$

For COPD patients, respiratory-specific quality of life was assessed using the validated revised Airways Questionnaire 20 (AQ20-R). ${ }^{22-24}$ Lower scores reflect more favorable health status. Physical quality of life as reflective of generic health status was measured using the ShortForm (SF)-12 Physical Component Summary (PCS) score. The SF-12 PCS is derived from the Medical Outcomes Study SF-36 instrument, which has been extensively validated in the general population and among adults with COPD. ${ }^{25},{ }^{26}$ Higher scores reflect more favorable health status. Although both the PCS and AQ20-R scores are continuous variables, they can be grouped for clinical interpretability. On an a priori basis, we divided these scores into 4 strata based on the quartiles observed in the COPD cohort.

\section{COPD Severity Assessment}

For subjects with COPD, COPD severity was assessed in several ways. We conducted spirometry according to American Thoracic Society (ATS) guidelines. ${ }^{27}$ Although we did not administer bronchodilators prior to spirometry, $90 \%$ of subjects had taken their own shortacting bronchodilator within 4 hours of spirometry or had taken a long-acting bronchodilator earlier in the same day.

Submaximal exercise performance was assessed using the Six Minute Walk Test (6MWT). ${ }^{28,}{ }^{29}$ Subjects who routinely used home oxygen or who had a resting oxygen saturation $<90 \%$ were supplied with supplemental oxygen during the test. The primary outcome was meters walked in 6 minutes.

Oxygen saturation was assessed at rest using pulse oximetry. For subjects with prescribed supplemental oxygen $(n=61)$, oxygen saturation was assessed on their prescribed oxygen.

We also used a previously-validated survey-based COPD severity score, which is based on responses to survey items that comprise five domains of COPD severity: (1) degree of respiratory symptoms, (2) prior systemic corticosteroid use, (3) other COPD medication use, 
(4) previous hospitalization or intubation for respiratory disease, and (5) home oxygen use. ${ }^{30}$ Potential scores range from 0 to 35 .

We furthermore determined the BODE Index, which is a multidimensional score, predictive of death in COPD, that incorporates many of the above measures. ${ }^{31}$ Specifically, it includes body-mass index (BMI) [B], airflow obstruction as measured by $\mathrm{FEV}_{1}[\mathrm{O}]$ dyspnea [D], and exercise capacity [E], measured by the 6MWT.

\section{Statistical Analysis}

Differences in characteristics between COPD subjects and referents were compared using the t-test for continuous normally distributed variables and $\chi^{2}$ tests for categorical variables. We used $\chi^{2}$ tests for linear trend for ordinal variables.

Risk of Depressive Symptoms Relative to Referents-We used multivariate logistic regression to determine the adjusted odds ratio (OR) of having depressive symptoms in COPD subjects relative to referents, taking into account sociodemographics and comorbidities. We analyzed the COPD group as a whole relative to referents and also stratified by degree of airway obstruction as measured by $\mathrm{FEV}_{1} \%$ predicted categorizations specified by GOLD. ${ }^{16}$ We used likelihood ratio testing to determine whether different OR's within a given multivariate logistic regression were different from each other.

COPD Severity and Risk of Depression-To further evaluate whether COPD is associated with depression, we examined whether higher COPD severity was associated with a greater likelihood of having depressive symptoms. To do so, we developed several multivariate logistic regression models. Each model used depressive symptoms as the outcome variable and included the same potential confounders (sociodemographics, comorbidities, tobacco history, and BMI) but included a different measure of COPD severity as a predictor variable.

Impact of Depression on Quality of Life among COPD Patients-We also evaluated the association between depressive symptoms and health-related quality of life, controlling for COPD severity. Here we developed two multivariate logistic regression models, each with a different quality of life outcome variable. Each model incorporated the same potential confounders, listed above, as well as both the BODE Index and COPD Severity Score to adjust for COPD severity. We chose the BODE index because, as a single measure, it incorporates multiple measures of COPD severity, including $\mathrm{FEV}_{1}$ and 6MWT. We also incorporated the COPD Severity Score because, as a survey-based measure of such factors as COPD-specific utilization, it has the potential to capture a dimension of COPD severity not assessed by the BODE Index. Because our objective here was to determine the extent to which depressive symptoms are associated with quality of life after maximally adjusting for COPD severity, it was most conservative to simultaneously include both the BODE Index and COPD Severity Score. For our categorizations of overall physical and respiratory-specific quality of life, we used ordinal logistic regression. ${ }^{32}$ The ordinal logistic model invokes the proportional odds assumption and estimates a single OR for the association between a predictor and a multilevel categorical outcome (in this case, the 4 strata of the PCS and AQ20-R).

For all analyses, we used Stata/SE software (version 9.2, College Station, TX). For all logistic regression models, the Hosmer-Lemeshow test demonstrated adequate goodness-of-fit ( $p>0.20$ for all models). ${ }^{32}$ The proportional odds assumption was verified for both ordinal logistic regression analyses $\left(\mathrm{p}>0.20\right.$ for both models). ${ }^{32}$ 


\section{RESULTS}

\section{Patient Characteristics}

By design, patients with and without COPD were similar in age, gender, and race (TABLE 1). Compared with referents, patients with COPD had a higher prevalence of all examined comorbidities, higher average BMI, and greater prevalence of depressive symptoms $(\mathrm{p}<.001$ for all).

\section{COPD and the Risk of Depressive Symptoms}

In multivariate analysis adjusting for sociodemographics and comorbidities, depressive symptoms were much more common in persons with COPD than in referents (OR, 3.6; 95\% $\mathrm{CI}, 2.1-6.1 ; \mathrm{p}<.001)$. In addition, when COPD subjects were stratified by $\mathrm{FEV}_{1}$ categorization, all subgroups were more likely to have depressive symptoms relative to referents, with the OR highest among those with the lowest $\mathrm{FEV}_{1}$ (TABLE 2). A $\chi^{2}$ test for trend revealed that greater COPD severity, based on greater categorical impairment in $\mathrm{FEV}_{1}$, was associated with increasing risk of depressive symptoms $(\mathrm{p}<.001)$.

To examine whether COPD severity unmeasured by lung function might explain why patients with higher $\mathrm{FEV}_{1}$ manifest greater odds of depressive symptoms than referents, we dichotomized subjects based on the median value of the COPD Severity Score within each $\mathrm{FEV}_{1} \%$ predicted stratum (TABLE 3 ). Thus, for example, the median value of the COPD Severity Score in the subgroup of patients with $\mathrm{FEV}_{1} \geq 80 \%$ predicted was 7 . Patients in this subgroup whose COPD Severity Score was above the median (i.e. $\geq 7$ ) were at greater risk of having depressive symptoms relative to the referent population (OR, 4.3, 95\% CI $2.3-8.0$ ) than patients in this subgroup whose COPD Severity Score was below the median (i.e. <7) (OR, 1.8; 95\% CI 0.9-3.8); likelihood ratio testing revealed that the OR of 4.3 was statistically significantly different than the OR of $1.8(\mathrm{p}=0.009)$. This result suggests that variability in COPD severity is related to variability in depressive symptoms even in subjects with higher $\mathrm{FEV}_{1}$.

Among the subgroup with COPD, greater COPD severity was associated with increased likelihood of depressive symptoms after controlling for covariates. This was observed for each method used to assess COPD severity (TABLE 4).

\section{Depressive Symptoms and Quality of Life in COPD}

When examining the relationship between depressive symptoms and health-related quality of life, after adjusting for both potential confounders and COPD severity measures, we found that depressive symptoms were strongly associated with worse respiratory-specific quality of life (OR, 3.6; 95\% CI $2.7-4.8 ; \mathrm{p}<.001)$ and worse overall physical quality of life (OR, 2.4; 95\% CI, $1.8-3.2 ; \mathrm{p}<.001)$ (TABLE 5).

\section{DISCUSSION}

In a population-based sample, COPD was associated with a greater risk of depressive symptoms compared to a matched referent group. The fact that increasing COPD severity is associated with an increasing likelihood of depressive symptoms provides further evidence for an association between COPD and depression. Depressive symptoms also appeared to negatively impact quality of life, highlighting the importance of depression in these patients. Targeting depression in COPD could therefore be an attractive strategy to improve health status.

Previous research on the risk of depression faced by patients with COPD has yielded conflicting results. ${ }^{5-13}$ The study by van Manen and colleagues, ${ }^{11}$ with 162 COPD subjects, is the largest 
prior study on this subject that also included both a referent population and pulmonary function measurement. Interestingly, this study showed an increase in depressive symptoms among subjects with severe COPD ( $\mathrm{FEV}_{1}<50 \%$ of predicted) but not in their cohort as a whole or in the less severe subgroups. ${ }^{11} \mathrm{We}$ cannot be sure of the reason for our differing conclusions, but this may have to do with higher rates of mood disorders generally in the United States relative to The Netherlands, where that study was performed. ${ }^{33}$ Prior research has suggested that cultural differences between nations may affect the expression of depressive symptoms and be responsible for differing risk factors for major depression in various countries. ${ }^{34}$

Our finding that higher COPD severity is associated with a higher likelihood of depressive symptoms provides further validity to the concept that COPD is associated with depression. However, our cross-sectional analysis cannot completely determine the causal pathway between COPD and depressive symptoms. It is possible that COPD causes depression or that depression causes COPD via its association with cigarette smoking. ${ }^{35}$ Both pathways may also be operative. Alternatively, shared genetic and environmental factors may predispose independently to both smoking and depression. ${ }^{36,37}$ Thus, because COPD may not be directory causing depression, targeting improved respiratory physiology in COPD may not alleviate depressive symptoms.

We found that depressive symptoms were strongly associated with health-related quality of life. Even though the risk of depressive symptoms increased with increasing COPD severity, the relationship between depressive symptoms and health-related quality of life was present taking into account such severity. These results are particularly important because depression complicating COPD is often overlooked in clinical practice. ${ }^{37}$ Our results suggest that attempts to improve the quality of life of COPD patients should not underestimate the importance of depression as a potentially mediating factor. Moreover, there is evidence that treating depression in COPD improves quality of life. ${ }^{38,} 39$ Although this might include antidepressive pharmacotherapy, ${ }^{39}$ interventions such as pulmonary rehabilitation, which often includes psychosocial support, may also improve mood and reduce depressive symptoms. ${ }^{4}, 40-42$ Alternatively, psychological counseling within the context of a physician visit may be important. ${ }^{43}$ Because of the strong association between depressive symptoms and quality of life, further study regarding effective methods of treating depression in COPD appear clearly warranted.

Several study limitations must be considered. Although the inclusion criteria required healthcare utilization for COPD and COPD medication usage, it is possible that some subjects had asthma rather than COPD. However, all patients also had a physician diagnosis of COPD and reported having the condition. The observed lifetime smoking prevalence was similar to that in other population-based epidemiologic studies of COPD, supporting the diagnosis of COPD rather than asthma. ${ }^{44,}{ }^{45}$ Nonetheless, we cannot exclude the possibility that some subjects, especially those with less obstruction on spirometry, may have conditions other than COPD. However, we note that reduced $\mathrm{FEV}_{1}$ was associated with a higher likelihood of depressive symptoms; thus, eliminating subjects with higher $\mathrm{FEV}_{1}$ from our cohort would only have strengthened our finding that subjects with COPD are at higher risk of depressive symptoms than referents.

Because an important focus in the prospective follow-up of our cohort will be studying the long-term prevention of COPD-associated morbidities, we intentionally sampled younger adults with COPD (ages 40-65). Although we adjusted for age within our multivariate models, we cannot be sure of the applicability of our results to older adults with COPD. In addition, KP members, because they have health care access, may also be different than the general population of adults with COPD. Mitigating this limitation, the sociodemographic characteristics of Northern California KP members are similar to those of the regional 
population. ${ }^{46,}{ }^{47}$ Moreover, selection bias could have been introduced by non-participation in the study and could in turn affect the generalizability of our results. However, our participation rates were comparable or better than many other studies on this subject. ${ }^{1,}, 6,7,9-13$

Our measure of depression, the GDS, is not intended to diagnose major depression but rather depressive symptoms. Nonetheless, patients with depressive symptoms warrant further evaluation in clinical practice, and treatment for depression is often recommended even in the absence of a diagnosis of major depression. ${ }^{48}$ One advantage of the GDS over other measures of depressive symptoms is that it is less contaminated with somatic symptoms such as poor appetite and poor sleep that may be symptoms of either depression or of COPD itself. ${ }^{9,} 11$ This reduces the likelihood that we are over-estimating depression in this setting.

In conclusion, we found that patients with COPD, at all levels of airway obstruction, were at higher risk of depressive symptoms than referents. Furthermore, increasing COPD severity was associated with an increasing likelihood of depressive symptoms. Even so, after taking COPD severity into account, depressive symptoms were strongly associated with worse quality of life.

\section{Clinical Significance}

- COPD is associated with an increased risk of depressive symptoms. Clinicians should thus be alert to the possibility of depression in their COPD patients.

- Because depressive symptoms appear to strongly impact quality of life in COPD, even after adjusting for respiratory symptoms and impairment, clinicians should consider depression in COPD to be an important clinical problem in its own right.

\section{Acknowledgments}

FUNDING: Dr. Omachi was supported by National Heart, Lung, and Blood Institute, grant number T32 HL007185. Dr. Eisner was supported by R01HL077618 National Heart, Lung, and Blood Institute, National Institutes of Health and UCSF Bland Lane FAMRI Center of Excellence on Secondhand Smoke CoE2007.

\section{References}

1. Ruo B, Rumsfeld JS, Hlatky MA, Liu H, Browner WS, Whooley MA. Depressive symptoms and health-related quality of life: the Heart and Soul Study. Jama Jul 9;2003 290(2):215-221. [PubMed: 12851276]

2. Wijkstra PJ, Ten Vergert EM, van Altena R, et al. Long term benefits of rehabilitation at home on quality of life and exercise tolerance in patients with chronic obstructive pulmonary disease. Thorax Aug;1995 50(8):824-828. [PubMed: 7570431]

3. Goldstein RS, Gort EH, Stubbing D, Avendano MA, Guyatt GH. Randomised controlled trial of respiratory rehabilitation. Lancet Nov 19;1994 344(8934):1394-1397. [PubMed: 7968075]

4. Lacasse Y, Martin S, Lasserson TJ, Goldstein RS. Meta-analysis of respiratory rehabilitation in chronic obstructive pulmonary disease. A Cochrane systematic review. Eura Medicophys Dec;2007 43(4): 475-485. [PubMed: 18084170]

5. Norwood R, Balkissoon R. Current perspectives on management of co-morbid depression in COPD. Copd Mar;2005 2(1):185-193. [PubMed: 17136980]

6. Felker B, Katon W, Hedrick SC, et al. The association between depressive symptoms and health status in patients with chronic pulmonary disease. Gen Hosp Psychiatry Mar-Apr;2001 23(2):56-61. [PubMed: 11313071]

7. Kim HF, Kunik ME, Molinari VA, et al. Functional impairment in COPD patients: the impact of anxiety and depression. Psychosomatics Nov-Dec;2000 41(6):465-471. [PubMed: 11110109]

8. Wamboldt FS. Anxiety and depression in COPD: a call (and need) for further research. Copd Jun;2005 2(2):199-201. [PubMed: 17136945] 
9. van Ede L, Yzermans CJ, Brouwer HJ. Prevalence of depression in patients with chronic obstructive pulmonary disease: a systematic review. Thorax Aug;1999 54(8):688-692. [PubMed: 10413720]

10. McSweeny AJ, Grant I, Heaton RK, Adams KM, Timms RM. Life quality of patients with chronic obstructive pulmonary disease. Arch Intern Med Mar;1982 142(3):473-478. [PubMed: 7065785]

11. van Manen JG, Bindels PJ, Dekker FW, CJ IJ, van der Zee JS, Schade E. Risk of depression in patients with chronic obstructive pulmonary disease and its determinants. Thorax May;2002 57(5):412-416. [PubMed: 11978917]

12. Engstrom CP, Persson LO, Larsson S, Ryden A, Sullivan M. Functional status and well being in chronic obstructive pulmonary disease with regard to clinical parameters and smoking: a descriptive and comparative study. Thorax Aug;1996 51(8):825-830. [PubMed: 8795672]

13. Isoaho R, Keistinen T, Laippala P, Kivela SL. Chronic obstructive pulmonary disease and symptoms related to depression in elderly persons. Psychol Rep Feb;1995 76(1):287-297. [PubMed: 7770581]

14. Eisner MD, Iribarren C, Yelin EH, et al. Pulmonary Function and the Risk of Functional Limitation in Chronic Obstructive Pulmonary Disease. Am J Epidemiol May 1;2008 167(9):1090-1101. [PubMed: 18343879]

15. Sidney S, Sorel M, Quesenberry CP Jr, DeLuise C, Lanes S, Eisner MD. COPD and incident cardiovascular disease hospitalizations and mortality: Kaiser Permanente Medical Care Program. Chest Oct;2005 128(4):2068-2075. [PubMed: 16236856]

16. Pauwels RA, Buist AS, Calverley PM, Jenkins CR, Hurd SS. Global strategy for the diagnosis, management, and prevention of chronic obstructive pulmonary disease. NHLBI/WHO Global Initiative for Chronic Obstructive Lung Disease (GOLD) Workshop summary. American Journal of Respiratory and Critical Care Medicine Apr;2001 163(5):1256-1276. [PubMed: 11316667]

17. Rule BG, Harvey HZ, Dobbs AR. Reliability of the Geriatric Depression Scale for younger adults. 1989;9(2):37-43.

18. Mancuso CA, Peterson MG, Charlson ME. Effects of depressive symptoms on health-related quality of life in asthma patients. J Gen Intern Med May;2000 15(5):301-310. [PubMed: 10840265]

19. Ferraro FR, Chelminski I. Preliminary normative data on the Geriatric Depression Scale-Short Form (GDS-SF) in a young adult sample. J Clin Psychol Jul;1996 52(4):443-447. [PubMed: 8842881]

20. Gerety MB, Williams JW Jr, Mulrow CD, et al. Performance of case-finding tools for depression in the nursing home: influence of clinical and functional characteristics and selection of optimal threshold scores. J Am Geriatr Soc Oct;1994 42(10):1103-1109. [PubMed: 7930337]

21. Whooley MA, Browner WS. Association between depressive symptoms and mortality in older women. Study of Osteoporotic Fractures Research Group. Arch Intern Med Oct 26;1998 158(19): 2129-2135. [PubMed: 9801180]

22. Chen H, Eisner MD, Katz PP, Yelin EH, Blanc PD. Measuring disease-specific quality of life in obstructive airway disease: validation of a modified version of the airways questionnaire 20 . Chest Jun;2006 129(6):1644-1652. [PubMed: 16778287]

23. Hajiro T, Nishimura K, Jones PW, et al. A novel, short, and simple questionnaire to measure healthrelated quality of life in patients with chronic obstructive pulmonary disease. Am J Respir Crit Care Med Jun;1999 159(6):1874-1878. [PubMed: 10351933]

24. Alemayehu B, Aubert RE, Feifer RA, Paul LD. Comparative analysis of two quality-of-life instruments for patients with chronic obstructive pulmonary disease. Value Health Sep-Oct;2002 5 (5):437-442. [PubMed: 12201861]

25. Benzo R, Flume PA, Turner D, Tempest M. Effect of pulmonary rehabilitation on quality of life in patients with COPD: the use of SF-36 summary scores as outcomes measures. J Cardiopulm Rehabil Jul-Aug;2000 20(4):231-234. [PubMed: 10955263]

26. Ware J Jr, Kosinski M, Keller SD. A 12-Item Short-Form Health Survey: construction of scales and preliminary tests of reliability and validity. Med Care Mar;1996 34(3):220-233. [PubMed: 8628042]

27. American Thoracic Society. Standardization of Spirometry, 1994 Update. Am J Respir Crit Care Med 1995;152(3):1107-1136. [PubMed: 7663792]

28. ATS statement: guidelines for the six-minute walk test. American Journal of Respiratory and Critical Care Medicine Jul 1;2002 166(1):111-117. [PubMed: 12091180]

29. Fishman AP. Pulmonary rehabilitation research. Am J Respir Crit Care Med Mar;1994 149(3 Pt 1): 825-833. [PubMed: 8118655] 
30. Eisner MD, Trupin L, Katz PP, et al. Development and validation of a survey-based COPD severity score. Chest Jun;2005 127(6):1890-1897. [PubMed: 15947299]

31. Celli BR, Cote CG, Marin JM, et al. The body-mass index, airflow obstruction, dyspnea, and exercise capacity index in chronic obstructive pulmonary disease. N Engl J Med Mar 4;2004 350(10):10051012. [PubMed: 14999112]

32. Hosmer, DW.; Lemeshow, S. Applied logistic regression. Vol. 2. Hoboken, NJ: John Wiley \& Sons, Inc; 2000.

33. Bijl RV, de Graaf R, Hiripi E, et al. The prevalence of treated and untreated mental disorders in five countries. Health Aff (Millwood) May-Jun;2003 22(3):122-133. [PubMed: 12757277]

34. Weissman MM, Bland RC, Canino GJ, et al. Cross-national epidemiology of major depression and bipolar disorder. Jama Jul 24-31;1996 276(4):293-299. [PubMed: 8656541]

35. Wagena EJ, Kant I, van Amelsvoort LG, Wouters EF, van Schayck CP, Swaen GM. Risk of depression and anxiety in employees with chronic bronchitis: the modifying effect of cigarette smoking. Psychosom Med Sep-Oct;2004 66(5):729-734. [PubMed: 15385698]

36. Kendler KS, Neale MC, MacLean CJ, Heath AC, Eaves LJ, Kessler RC. Smoking and major depression. A causal analysis. Arch Gen Psychiatry Jan;1993 50(1):36-43. [PubMed: 8422220]

37. Wagena EJ, Huibers MJ, van Schayck CP. Antidepressants in the treatment of patients with COPD: possible associations between smoking cigarettes, COPD and depression. Thorax Aug;2001 56(8): 587-588. [PubMed: 11462058]

38. Simon GE, Von Korff M, Lin E. Clinical and functional outcomes of depression treatment in patients with and without chronic medical illness. Psychol Med Feb;2005 35(2):271-279. [PubMed: 15841684]

39. Borson S, McDonald GJ, Gayle T, Deffebach M, Lakshminarayan S, VanTuinen C. Improvement in mood, physical symptoms, and function with nortriptyline for depression in patients with chronic obstructive pulmonary disease. Psychosomatics Spring;1992 33(2):190-201. [PubMed: 1557484]

40. Coventry PA, Hind D. Comprehensive pulmonary rehabilitation for anxiety and depression in adults with chronic obstructive pulmonary disease: Systematic review and meta-analysis. J Psychosom Res Nov;2007 63(5):551-565. [PubMed: 17980230]

41. Withers NJ, Rudkin ST, White RJ. Anxiety and depression in severe chronic obstructive pulmonary disease: the effects of pulmonary rehabilitation. J Cardiopulm Rehabil Nov-Dec;1999 19(6):362365. [PubMed: 10609186]

42. Paz-Diaz H, Montes de Oca M, Lopez JM, Celli BR. Pulmonary rehabilitation improves depression, anxiety, dyspnea and health status in patients with COPD. Am J Phys Med Rehabil Jan;2007 86(1): 30-36. [PubMed: 17304686]

43. Kunik ME, Braun U, Stanley MA, et al. One session cognitive behavioural therapy for elderly patients with chronic obstructive pulmonary disease. Psychol Med May;2001 31(4):717-723. [PubMed: 11352373]

44. Eisner MD, Balmes J, Katz PP, Trupin L, Yelin EH, Blanc PD. Lifetime environmental tobacco smoke exposure and the risk of chronic obstructive pulmonary disease. Environ Health 2005;4(1):7. [PubMed: 15890079]

45. Mannino DM, Homa DM, Akinbami LJ, Ford ES, Redd SC. Chronic obstructive pulmonary disease surveillance--United States, 1971-2000. MMWR Surveillance Summaries Aug 2;2002 51(6):1-16.

46. Karter AJ, Ferrara A, Liu JY, Moffet HH, Ackerson LM, Selby JV. Ethnic disparities in diabetic complications in an insured population. Jama May 15;2002 287(19):2519-2527. [PubMed: 12020332]

47. Krieger N. Overcoming the absence of socioeconomic data in medical records: validation and application of a census-based methodology. American Journal of Public Health 1992;82(5):703-710. [PubMed: 1566949]

48. Anderson IM, Nutt DJ, Deakin JF. Evidence-based guidelines for treating depressive disorders with antidepressants: a revision of the 1993 British Association for Psychopharmacology guidelines. British Association for Psychopharmacology. J Psychopharmacol Mar;2000 14(1):3-20. [PubMed: 10757248] 
Table 1

Characteristics of 1202 patients with COPD and 302 referents*

\begin{tabular}{|c|c|c|c|}
\hline & Referents $(n=302)$ & COPD Patients (n=1202) & P Value \\
\hline \multicolumn{4}{|l|}{ Demographic Factors } \\
\hline Age, mean $(\mathrm{SD})$ years & $58.5(6.2)$ & $58.2(6.2)$ & .49 \\
\hline Female & $185(61)$ & $691(57)$ & .23 \\
\hline White (non-Hispanic) & $200(66)$ & $810(67)$ & .70 \\
\hline Married or Cohabitating & $200(66)$ & $744(62)$ & .16 \\
\hline College graduate & $165(55)$ & $326(27)$ & $<.001$ \\
\hline Annual household income $<\$ 20,000$ & $9(3)$ & $129(11)$ & $<.001$ \\
\hline \multicolumn{4}{|l|}{ Medical Co-morbidities } \\
\hline Hypertension & $118(39)$ & $657(55)$ & $<.001$ \\
\hline Coronary artery disease & $8(3)$ & $139(12)$ & $<.001$ \\
\hline Congestive heart failure & $0(0)$ & $136(11)$ & $<.001$ \\
\hline Stroke & $2(1)$ & $66(5)$ & $<.001$ \\
\hline Diabetes mellitus & $41(14)$ & $249(21)$ & $<.001$ \\
\hline Lower back pain & $98(32)$ & $707(59)$ & $<.001$ \\
\hline Sleep apnea & $27(9)$ & $265(22)$ & $<.001$ \\
\hline Tobacco history & & & $<.001$ \\
\hline Never smoker & $158(52)$ & $165(14)$ & \\
\hline Ex-smoker & $132(44)$ & $644(54)$ & \\
\hline Current Smoker & $12(4)$ & $393(33)$ & \\
\hline Body mass index (mean) (SD), $\mathrm{kg} / \mathrm{m}^{2}$ & $29.9(6.4)$ & $31.7(8.2)$ & $<.001$ \\
\hline Depressive Symptoms ${ }^{\dagger}$ & $17(6)$ & $330(27)$ & $<.001$ \\
\hline
\end{tabular}


Table 2

Prevalence and odds of depression in patients with COPD compared to referents

\begin{tabular}{llcc}
\hline & $\mathbf{n}$ & Depressive Symptoms ${ }^{*}$ & OR $^{\dagger}$ (95\% CI) \\
\hline COPD subjects & & & $3.1(1.7$ to 5.6$)$ \\
$\mathrm{FEV}_{1} \geq 80 \%$ predicted & 283 & $75(26.5 \%)$ & $2.9(1.7$ to 5.1$)$ \\
$\mathrm{FEV}_{1} \geq 50-80 \%$ predicted & 549 & $142(25.9 \%)$ & $4.6(2.5$ to 8.4$)$ \\
$\mathrm{FEV}_{1} \geq 30-50 \%$ predicted & 258 & $74(28.7 \%)$ & $8.0(4.1$ to 15.7$)$ \\
$\mathrm{FEV}_{1}<30 \%$ predicted & 112 & $39(34.8 \%)$ & 1.0 (referent) \\
\hline Referents & 302 & $17(5.6 \%)$ & \\
\hline
\end{tabular}

* Geriatric depression score $\geq 6$

$$
+
$$

${ }^{\dagger}$ Odds ratio for COPD vs. referents for each subgroup of COPD. Results are from multivariate logistic regression adjusted for age, gender, marital status, race, education, annual household income, body-mass index, and all comorbidities listed in Table 1. Other factors associated with depressive symptoms in multivariate analysis were age, gender, education, annual household income, bmi, and history of stroke, sleep apnea, and lower back pain ( $\mathrm{p}<.05$ for all). In $\chi^{2}$ test for trend, decreasing FEV 1 categorizations were associated with increasing odds of depressive symptoms ( $\left.\mathrm{p}<.001\right)$

${ }^{\ddagger}$ Comparing the whole COPD group to referents in multivariate analysis adjusted for the same covariates yields an odds ratio for depressive symptoms of 3.6 (95\% CI: $2.1-6.1$ ). 


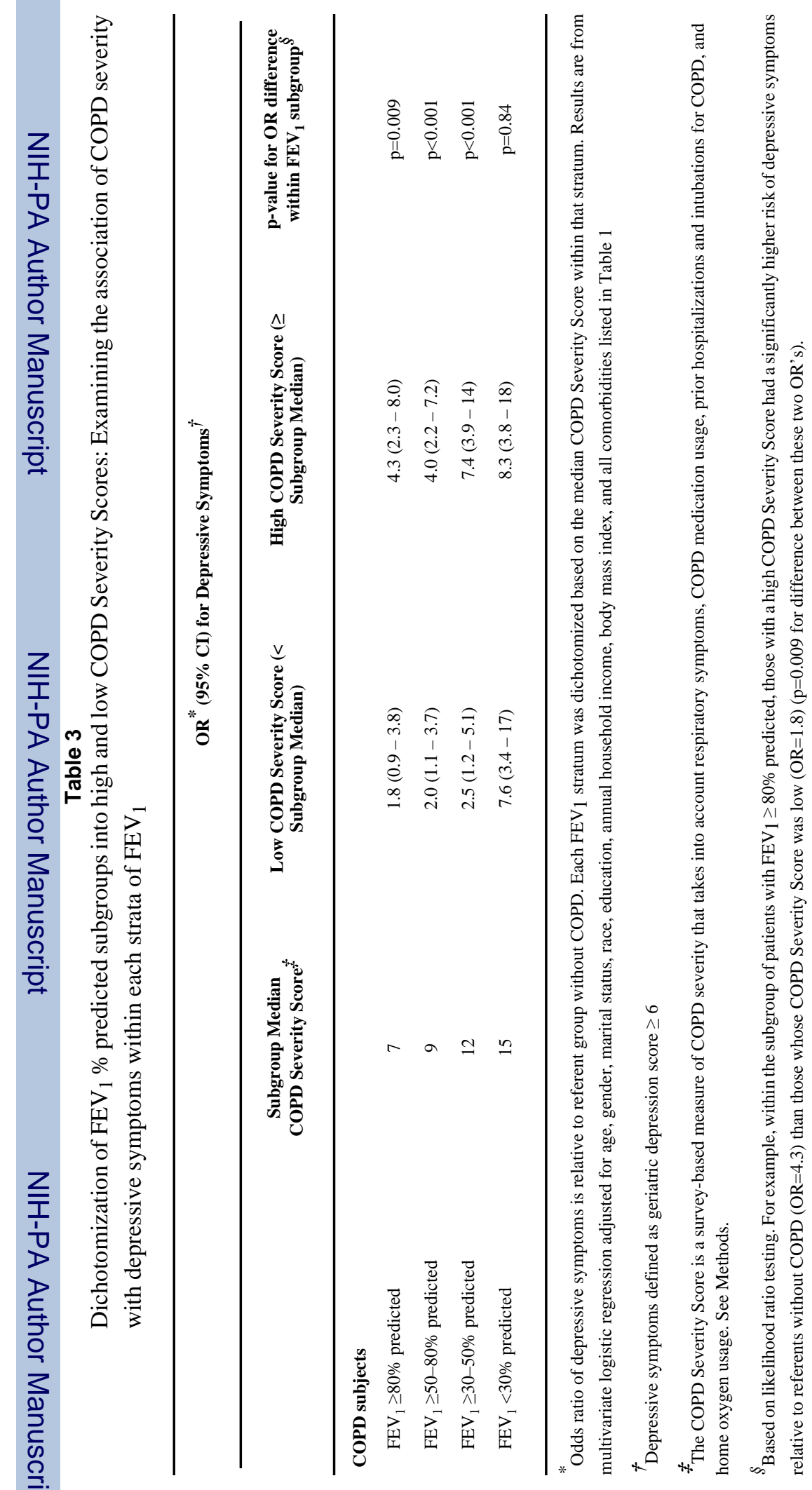




\section{Table 4}

Relationship of various measures of COPD severity to depressive symptoms (GDS Score $\geq 6$ ) among patients with COPD $(n=1202)$

\begin{tabular}{|c|c|c|}
\hline & OR $(95 \% \mathrm{CI})$ & P-Value \\
\hline $\mathrm{FEV}_{1} \%$ predicted $^{*}$ & $1.26(1.08-1.47)$ & 0.003 \\
\hline 6 Minute Walk Test ${ }^{*}$ & $1.96(1.64-2.34)$ & $<.001$ \\
\hline Oxygen Saturation ${ }^{*}$ & $1.33(1.15-1.55)$ & $<.001$ \\
\hline COPD Severity Score ${ }^{*}$ & $2.04(1.72-2.42)$ & $<.001$ \\
\hline BODE Index ${ }^{*}$ & $2.13(1.82-2.51)$ & $<.001$ \\
\hline
\end{tabular}

Each row represents a separate multivariate logistic regression analysis that includes the following covariates: age, gender, race, marital status, education, annual household income, tobacco history, body-mass index, and all comorbidities listed in Table 1.

*

Per 1 standard deviation in each of the measures: $\mathrm{FEV}_{1} \%$ predicted (unit decrement $=23 \%$ ); 6 minute walk test (unit decrement $=120$ meters); oxygen saturation (unit decrement 2.5\%); COPD Severity Score (unit increment [higher score reflects $\uparrow$ severity] = 6.1 points); BODE Index (unit increment [higher score reflects $\uparrow$ severity] $=2.4$ points). 
Table 5

Multivariate analyses of the association between depressive symptoms, COPD severity measures, and health-related quality of life in patients with COPD in multivariate analysis

\begin{tabular}{|c|c|c|c|c|}
\hline & \multicolumn{2}{|c|}{$\begin{array}{c}\text { Worse Respiratory-Specific Health-Related } \\
\text { Quality of Life }\end{array}$} & \multicolumn{2}{|c|}{$\begin{array}{l}\text { Worse Overall Physical Health-Related Quality } \\
\text { of Life }\end{array}$} \\
\hline & $\mathrm{OR}^{*}(95 \% \mathrm{CI})$ & P Value & $\mathrm{OR}^{*}(95 \% \mathrm{CI})$ & P Value \\
\hline Depressive Symptoms ${ }^{\dagger}$ & $3.6(2.7-4.8)$ & $<.001$ & $2.4(1.8-3.2)$ & $<.001$ \\
\hline BODE Index ${ }^{\ddagger}$ & $1.7(1.4-1.9)$ & $<.001$ & $2.0(1.7-2.3)$ & $<.001$ \\
\hline COPD Severity Score ${ }^{\S}$ & $2.9(2.5-3.5)$ & $<.001$ & $1.9(1.6-2.2)$ & $<.001$ \\
\hline
\end{tabular}

The two columns of health-related quality of life measures represent two different multivariate models which simultaneously included the independent variables shown above as well as the following covariates: age, gender, race, marital status, education, annual household income, tobacco history, body mass index, and all comorbidities listed in Table 1.

*

* Odds ratio from ordinal logistic regression, representing the association between predictor variables (e.g. presence of depressive symptoms) and the multi-level categorical health-related quality of life outcomes (see Methods).

${ }^{\dagger}$ Geriatric depression score $\geq 6$.

${ }^{\ddagger}$ Odds ratios presented per 1 standard deviation increment in BODE Index. The BODE Index includes body-mass index, pulmonary function measurement, a dyspnea scale, and exercise capacity (see Methods). Higher BODE Index scores reflect greater COPD severity.

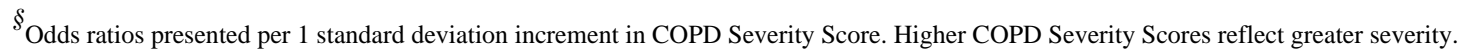

